\title{
An In Vivo Comparison of the Orientation of the Transverse Acetabular Ligament and the Acetabulum
}

\author{
Andrew R. Griffin, MPhty, BSc(ExSc\&Nutrition), Diana M. Perriman, PhD, MSc, BAppSc (Physio), \\ Claire J. Bolton, MBBS, BSc, Paul N. Smith, BMBS, FRACS (Ortho)
}

Trauma and Orthopaedic Research Unit, The Canberra Hospital, Canberra, Australia

Department of Medicine, Australian National University, Canberra, Australia

\section{A R T I C L E I N F O}

\section{Article history:}

Received 27 February 2013

Accepted 1 August 2013

\section{Keywords:}

transverse acetabular ligament

native acetabulum

acetabular component alignment

\begin{abstract}
A B S T R A C T
Aligning the acetabular component with the Transverse Acetabular Ligament (TAL) to ensure optimal anteversion has been reported to reduce dislocation rates. However, to our knowledge in vivo measurement of the TAL angle has not yet been reported in a large cohort of normal hips. CT scans of 218 normal hips were analyzed. The TAL and four acetabular rim anteversion angles were measured (superiorly to inferiorly) relative to the anterior pelvic plane. The mean TAL anteversion angle was $20.5^{\circ} \pm 7.0^{\circ}$, and the acetabular rim angles from superior to inferior were $11.0^{\circ} \pm 12.9^{\circ}, 19.9^{\circ} \pm 8.8^{\circ}, 20.9^{\circ} \pm 6.2^{\circ}$ and $25.1^{\circ} \pm 6.2^{\circ}$ respectively. Both the TAL and the acetabular rim were significantly more anteverted in females than in males. The TAL anteversion angle was comparable to the predominant orientation (central rim section) of the native acetabulum while the superior acetabulum was comparatively retroverted and the inferior was relatively more anteverted.
\end{abstract}

(c) 2014 Elsevier Inc. All rights reserved.
The transverse acetabular ligament (TAL) has been proposed as an accurate anatomical reference for guiding the optimal orientation the acetabular component in total hip arthroplasty (THA) [1-9]. Over 285,000 THAs were performed in the past year in the United States of America alone [10] and this number is predicted to rise $[11,12]$. Malalignment of the acetabular component has been reported to increase the risk of dislocation, accelerate component wear, and predispose the acetabulum to loosening [13,14]. Although post-operative dislocation rates have been reported to be as high as $2 \%-11 \%[7,15-17]$ the most recent Australian data suggest a rate of less than $1 \%$ [18]. Correct positioning of the acetabular cup has also been reported to be an important factor in preventing component wear after THA $[5,12,14,15,19-30]$.

Orientation of the acetabular component is defined by its inclination and anteversion [2,30,31]. In a retrospective radiographic review, Lewinnek and colleagues found a reduced risk of dislocation if the acetabular component is positioned such that the inclination is approximately $40^{\circ} \pm 10^{\circ}$, and the degree of anteversion is $15^{\circ} \pm 10^{\circ}$ $[32,33]$. Although Lewinnek's range of inclination angle is well accepted there is some contention as to the ideal degree of anteversion $[2,5,32,34]$. When positioning the acetabular component it is generally accepted that the orientation should conform to the 'safe zones'

The Conflict of Interest statement associated with this article can be found at http:// dx.doi.org/10.1016/j.arth.2013.08.002.

Reprint requests: Andrew Griffin, MPhty, BSc(ExSc\&Nut), c/o Dr Diana Perriman, Trauma and Orthopaedic Research Unit, Building 6, Level 1, The Canberra Hospital, PO Box 11, Woden ACT 2606, Australia. of between $5^{\circ}$ and $25^{\circ}$ of anteversion and $30^{\circ}$ to $50^{\circ}$ of inclination to minimize the risk of dislocation [24,32,34]. However, it has been suggested that the rate of dislocation can be reduced to $0.6 \%$ by using the transverse acetabular ligament (TAL) as a reference for acetabular cup alignment [4].

The TAL is a fibrocartilagenous structure that connects the horns of the acetabular notch and separates the acetabular fossa from the inferior hip joint recess [2,35-38]. The native acetabular orientation is reported to be between $15^{\circ}$ and $24^{\circ}$ of anteversion $[5,6]$ while the TAL-labrum plane has been reported to be approximately $23^{\circ}$ [9]. It has been suggested that the intraoperative use of the TAL as a landmark may reduce the risk of THA dislocation and component wear $[1,7,21,36]$. However, the relative version of the TAL in relation to the acetabular rim has not been reported in vivo in a normal population.

The purpose of this study was to determine the relative orientation of the TAL compared to the bony acetabulum in vivo in normal hips. We hypothesized that the angle of anteversion of the TAL would be the same as the angle of anteversion of the acetabular rim thereby providing a reliable anatomical landmark for reproducing native cup orientation in THA.

\section{Materials and Methods}

Study Design

This was a retrospective descriptive study of measurements taken from abdominal and pelvic computerized tomography scans (CT) 
conducted at the Canberra Hospital between January 2007 and December 2011. The study protocol was approved by the ACT Health Human Research Ethics Committee (ETHLR.11.162).

\section{Participants}

Patients over the age of 18 years with normal hip joint anatomy who received a CT scan of the 'Abdomen and Pelvis' between January 2007 to December 2011 at The Canberra Hospital were included in this study.

\section{Exclusion Criteria}

Patients were excluded if they had any abnormal hip pathology or the TAL was not clearly visible as a straight line between the two horns of the acetabular notch on 3D CT imaging. If the TAL was visible on one side but not the other, measurements of the acetabular rim from the visible side only were included in the results.

\section{Measurements Conducted}

Two observers (ARG and CJB) conducted all measurements after intra-observer and inter-observer reliability was established (ICC 2,1 : $\mathrm{TAL}=0.96$ and Acetabulum $=0.90 ; \mathrm{TAL}=0.95$ and Acetabulum $=0.95$ respectively). Pelvic and abdominal CT was performed using a Toshiba Aquilion 16 slice scanner. Hospital protocols dictate that patients are positioned supine and central in the gantry and images are obtained at $1 \mathrm{~mm}$ intervals at a rotation speed of $0.5 \mathrm{~s}$ from the pubic symphysis to the diaphragm. For this study the images were uploaded to OsiriX v.4.0 32-bit Digital Imaging and Communications in Medicine format (DICOM) Viewer (Kanteron Systems, Valencia). Scans were viewed and measured in a multiplanar reconstruction using 3D MPR format.

In the coronal plane the images were rotated to align with the anterior pelvic plane (APP) as described by Lewinnek et al [32] from which the version angles were referenced. The transverse plane was aligned using the 'tear drops' of the pelvis (inferior rims of the acetabular fossae and the parasagittal surface of the ilium). Because the scans were rotated to achieve true planar views, a correction angle was recorded (Fig. 1). This correction angle was used to calculate the degree of anteversion and retroversion.

The angle of the acetabular rim in relation to the true sagittal plane (version) was measured at the most supero-lateral point of the acetabular rim (Figs. 2A \& $3 \mathrm{~A}$ ), at $10 \mathrm{~mm}$ and $20 \mathrm{~mm}$ below this point

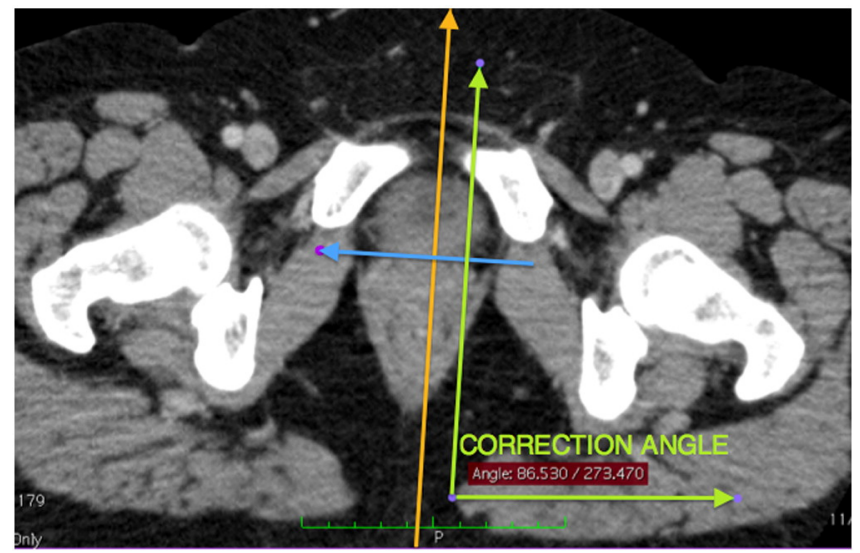

Fig. 1. Standardization and alignment of Images. Alignment of the anterior pelvic plane via anterior superior iliac spines with pubic tubercles. The Correction angle was the difference between the sagittal plane (perpendicular to the standardized coronal plane) and the horizontal.

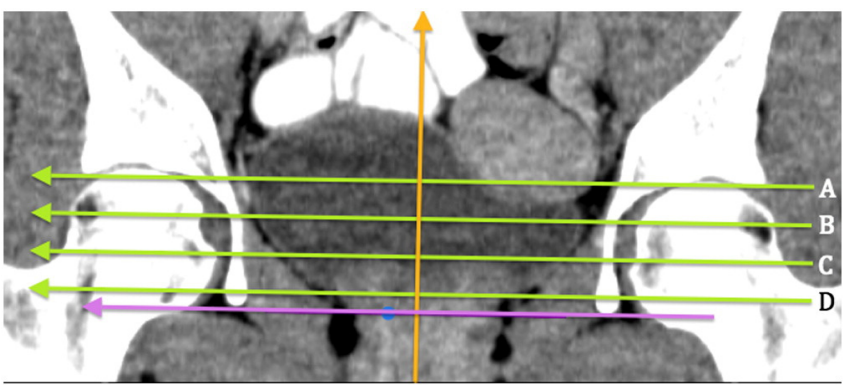

Fig. 2. Measurement of the Acetabular Rim. The acetabular rim was measured at the most superior point (A), $10 \mathrm{~mm}$ (B) and $20 \mathrm{~mm}$ inferior to this point (C), and finally at the inferior rim of the acetabulum (D). The most inferior line shows alignment of the transverse plane via the inferior rims of the acetabulae fossa.

(Fig. 2B \& C and Fig. 3B \& C respectively), and finally at the most inferior point of the acetabular rim (Figs. 2D \& 3D). These measurements were made for both the left and right sides when the TAL was visible.

The TAL lies in a parasagittal plane. Therefore, to be viewed as a straight line between the anterior and posterior horns of the acetabulum, the scan was rotated from the reference position (APP) until it was visible (Fig. 4A). The angle between the parasagittal plane in which the TAL was viewed and the APP was measured (Fig. 4B). The TAL angle was calculated by subtracting the correction angle from this angle. All angles were then subtracted from $90^{\circ}$ to conform with Murray's definition of radiographic anteversion [31] to allow accurate comparison with the existing literature [33].

In order to confirm that we were measuring the TAL from the CT images a cadaveric study was conducted. A cadaveric pelvis and hip were imaged pre-disarticulation following which two $1 \mathrm{~mm}$ tantalum beads which located the labral-TAL junctions were inserted. Subsequently, post-disarticulation imaging clearly identified that we had located the correct structure (Fig. 5).

\section{Statistical Analysis}

Descriptive statistics included means and standard deviations (mean $\pm \mathrm{SD}$ ). The data were tested for normality using the ShapiroWilk test. Normality was accepted if the $P$ value is $>0.05$. Because the data were normally distributed the TAL and the four acetabular rim angles were compared using paired t-tests (two tailed). The TAL and acetabular angles were compared for gender and side differences using an independent t-test (two-tailed). Statistical significance was accepted when $P<0.05$. A type 2, 1 intra-class correlation coefficient $\left(\mathrm{ICC}_{2,1}\right)$ was used to estimate inter-observer and intra-observer reliability. All data were analyzed using SPSS statistics base Version 20 (IBM, New York).

\section{Results}

CT scans for 160 patients were identified and from these 218 hips were measured i.e. only those hips where the TAL was clearly visible. One hundred and two hips were excluded because the TAL was insufficiently clear due to: obfuscation from surrounding tissue (53 hip scans), gross deformity of the joint due to arthritis (11 hip scans), artifact from prosthesis, plates or screws ( 8 hip scans) or where the CT scan did not include the lower acetabulum (30 hip scans). The mean age was 58.7 years (range, 20-96 years). The number of female and male hips reviewed was 111 and 107 respectively (Table 1 ).

The mean TAL anteversion angle was $20.5^{\circ} \pm 7.0^{\circ}$. The mean acetabular anteversion angles from superior to inferior at $10 \mathrm{~mm}$ intervals were $11.0^{\circ} \pm 12.9^{\circ}, 19.9^{\circ} \pm 8.8^{\circ}, 20.9^{\circ} \pm 6.2^{\circ}$ and $25.1^{\circ} \pm$ $6.2^{\circ}$ respectively. There was a significant difference between the TAL anteversion angle and the supero-lateral and inferior acetabular rim 

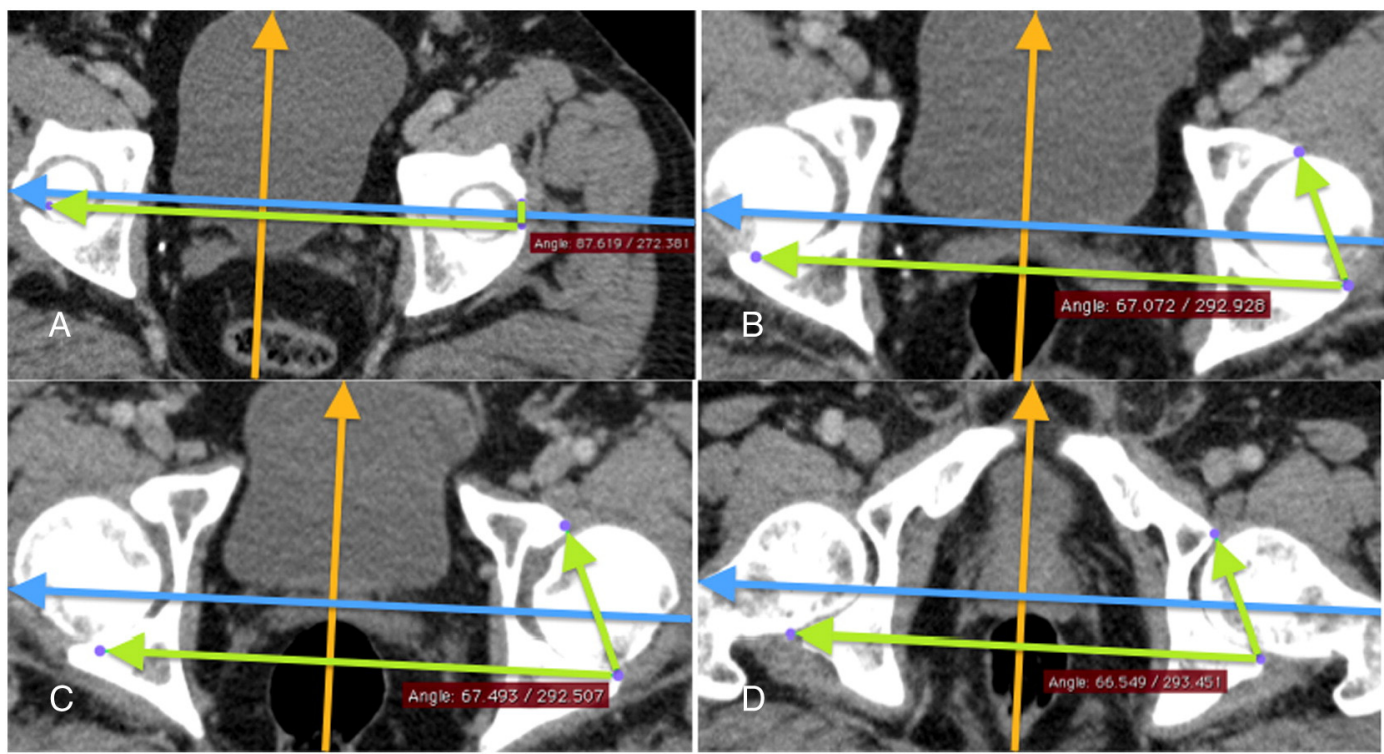

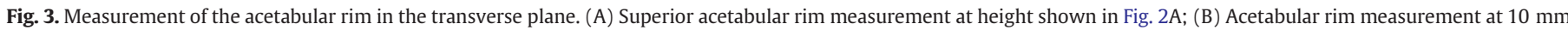

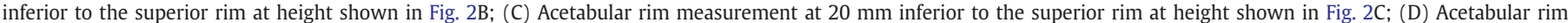
measurement at the most inferior margin of the acetabulum at height shown in Fig. 2D.
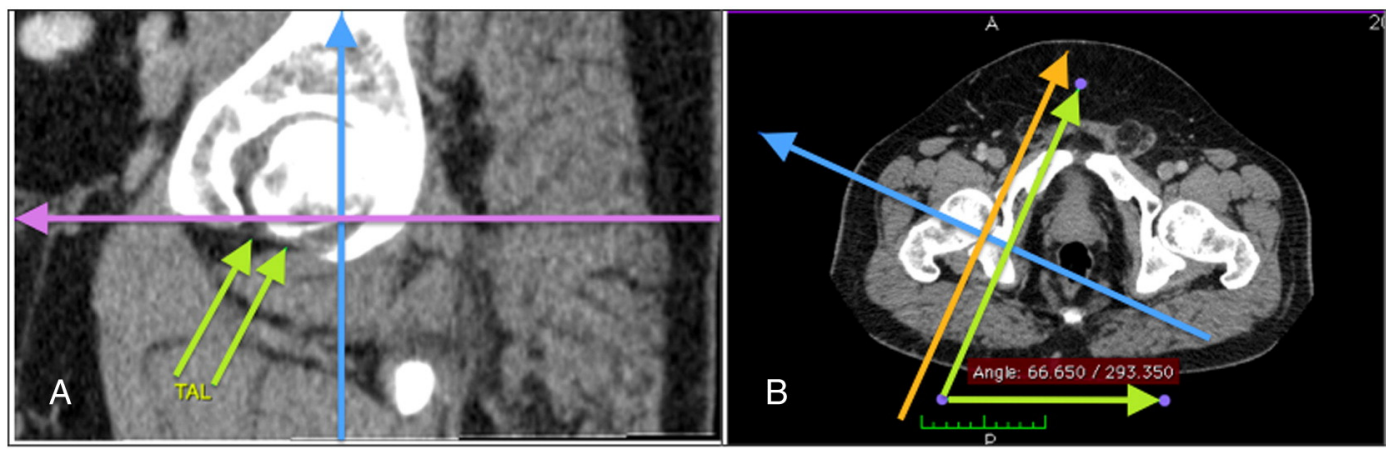

Fig. 4. Measurement of the parasagittal angle of the TAL in (A) the sagittal view and (B) the transverse view. Note: TAL $=$ Transverse Acetabular Ligament.

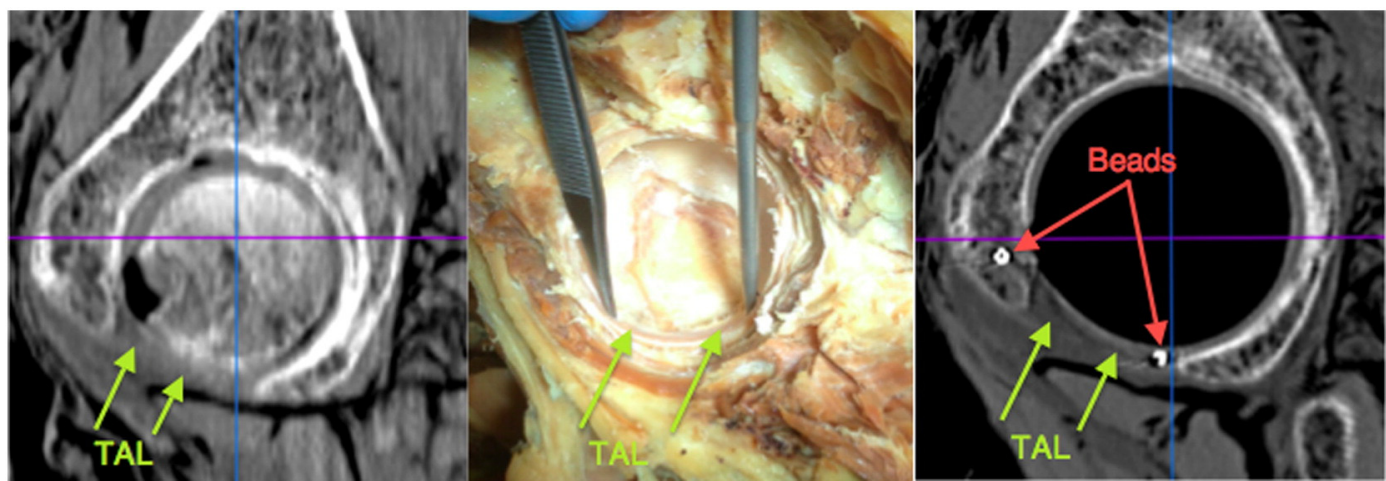

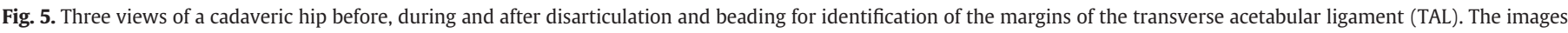
reveal that the CT methodology allowed accurate visualization of the TAL.

anteversion angle $(P<0.001$ and $P<0.001$ resp.). However, there was not a significant difference between the TAL anteversion angle and the rim anteversion angles at $10 \mathrm{~mm}$ and $20 \mathrm{~mm}$ inferior to the superior lateral rim (central rim section) (Table 2 and Fig. 6). The superior rim was retroverted outside Lewinneks 'safe zone' of $15^{\circ} \pm$ $10^{\circ}$ in $30.7 \%$ of cases $(n=67)$ and the inferior rim was anteverted outside Lewinneks ‘safe zone' in $53.7 \%$ of cases $(n=117)$ (Fig. 6$)$.
The mean TAL anteversion angle for males and females was $19.0^{\circ} \pm 6.3^{\circ}$ and $22.0^{\circ} \pm 7.4^{\circ}$ respectively. There was a significant difference between males and females for all acetabular and TAL anteversion angles (Table 2). Female average acetabular rims were anteverted between $2.7^{\circ}$ and $4.3^{\circ}$ more than males at different heights through the acetabulum, and the TAL was anteverted more in females by $3.0^{\circ}$ (Table 2 ). Anteversion of the TAL on the left and right sides of 
Table 1

Patient Characteristics.

\begin{tabular}{lc}
\hline Number of Patients (Hips Viewed) & $160(218)$ \\
Mean Age (range) & $58.7(20-96)$ \\
Gender (male/female) & $79 / 81$ \\
Gender of Hips measured (male/ female) & $107 / 111$ \\
\hline
\end{tabular}

the body was $20.1^{\circ}$ and $21.0^{\circ}$ respectively. There was no significant difference between left and right sides.

\section{Discussion}

The purpose of this study was to determine the relative orientation of the TAL compared to the acetabulum in vivo in normal hips. We hypothesized that the angle of anteversion of the TAL would be the same as the angle of anteversion of the acetabular rim thereby providing a reliable anatomical landmark for reproducing native cup orientation in THA.

There were three major findings from this study. First, the TAL was closely aligned with the central section of the acetabular rim which represented the predominant orientation. Second, the relative version of the acetabular rim changed considerably throughout the height of the acetabulum. The superior rim was relatively retroverted while the inferior rim was relatively anteverted. Relative to Lewinneks 'safe zone' a significant number of the acetabulae were retroverted superiorly $\left(<5^{\circ}\right)$ and excessively anteverted inferiorly $\left(>25^{\circ}\right)$. Finally, females were significantly more anteverted than males for both acetabular and TAL version angles, while there was no significant difference between left and right sides.

To our knowledge this is the first time the orientation of the TAL has been measured in vivo in a large cohort of normal hips. Alignment of the acetabular component during THA using the TAL has been proposed as a method for decreasing the post-operative dislocation rate and limiting excessive wear $[1-4,6,7,9,13,14,39,40]$. Previous studies have attempted to measure the orientation of the TAL using radiographic imaging and in vitro methods, but have been limited by imaging accuracy and subject numbers $[2,9,40]$. In this study we found that the orientation of the TAL was closely aligned with the central rim section of the acetabulum. Our findings are similar to the MRI arthrogram findings of Archbold et al [9] who reported a mean anteversion angle for the TAL of $23.0^{\circ} \pm 7.4^{\circ}$ for 25 patients with labral tears. In another paper Archbold et al reported an average postoperative acetabular component anteversion angle of $19.7^{\circ}$ when the TAL alone was used for alignment during THA [1]. This is consistent with our average TAL anteversion measurement of $20.5^{\circ}$ achieved using retrospective $\mathrm{CT}$ scans.

The orientation of the acetabular rim changed superiorly to inferiorly. The orientation of the TAL was significantly different $(P<0.001)$ from both the superior and inferior acetabular rim margins. In comparison to the TAL, the superior acetabular rim was relatively retroverted and the inferior acetabular rim was relatively anteverted,

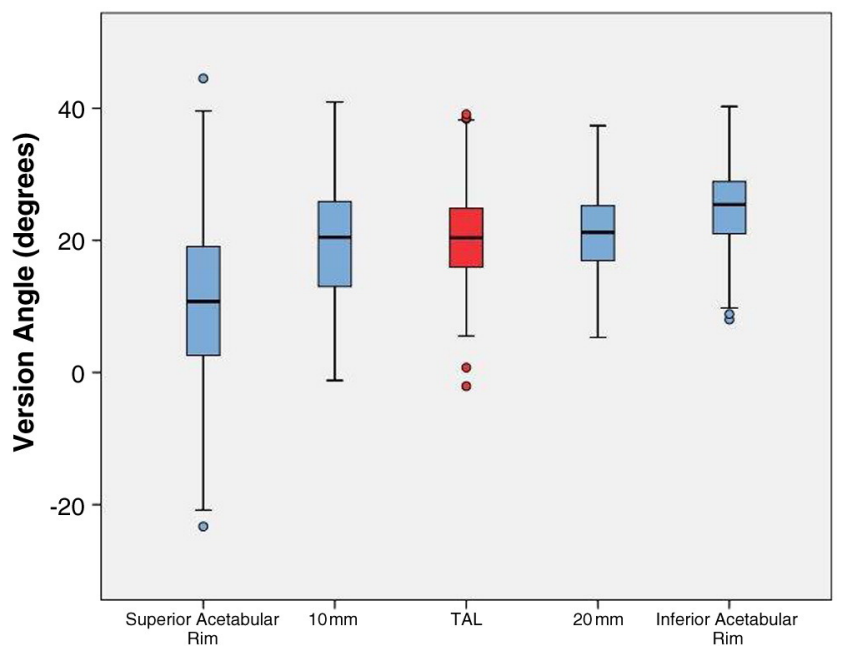

Fig. 6. Summary of the version angles measured for the TAL and the acetabular rim from superior to inferior. Note: TAL $=$ Transverse Acetabular Ligament. Box and whisker plot shows medians, quartiles and outliers.

while the closest match to alignment of the TAL occurred at the level of the central rim section which represented the predominant orientation. This finding reflects the torsional nature of the acetabular rim moving from a relatively retroverted position superiorly to a relatively anteverted position inferiorly. The degree of this torsion was variable both within and between patients. Vandenbussche et al [41] reported that acetabular anteversion is often assumed to be hemispheric and planar in its profile, but is in fact asymmetrical. These findings of acetabular asymmetry are well supported in the literature [41-43].

In this study there was a significant inter-individual difference in version measurements of the acetabular rim, particularly at the superior acetabular margin. While the inclination of the acetabulum (tilt relative to the sagittal plane) is consistently reported to be approximately $40^{\circ}$, reports of the degree of acetabular version is more variable $[6,41,42]$. The variation in version at the different acetabular levels found in this study may explain why other groups have reported such variable measurements. Our results showed the greatest degree of variation both within and between patients at the superior acetabulum $\left(11.0^{\circ} \pm 12.9^{\circ}\right)$, and the least variation at the inferior acetabulum $\left(25.1^{\circ} \pm 6.2^{\circ}\right)$. The variable version of the acetabular rim is clinically relevant because with respect to 'Lewinnek's safe zone', the superior acetabular rim was retroverted in $30.7 \%$ of scans, while the inferior rim was excessively anteverted in $53.7 \%$ of scans. Cups aligned outside Lewinnek's 'safe zone' have been associated with an increased dislocation rate [17].

Techniques for alignment of the acetabular cup remain controversial [44]. The ideal inclination and anteversion in THA are different for every patient [19]. Although Lewinnek's 'safe zone' is the most well known, others have suggested alternative and tighter limits $[7,32,45]$. Freehand positioning of the acetabular cup has been shown to be inaccurate $[3,7,26,46,47]$ while it is suggested that navigation

Table 2

Summary of Anteversion Measurements by Structure and Gender (Comparison With TAL and Gender).

\begin{tabular}{|c|c|c|c|c|c|c|}
\hline & $\begin{array}{l}\text { Average } \\
\text { Anteversion } \\
\text { (Degrees) }\end{array}$ & $\begin{array}{l}\text { Standard } \\
\text { Deviation } \\
\text { (Degrees) }\end{array}$ & $\begin{array}{l}P \text { Values } \\
\text { Comparison } \\
\text { With TAL }\end{array}$ & $\begin{array}{l}\text { Male Average } \\
\text { Anteversion } \\
\text { (Degrees) }\end{array}$ & $\begin{array}{l}\text { Female Average } \\
\text { Anteversion } \\
\text { (Degrees) }\end{array}$ & $\begin{array}{l}P \text { Values } \\
\text { Between } \\
\text { Genders }\end{array}$ \\
\hline TAL & 20.5 & 7.0 & & 19.0 & 22.0 & 0.001 \\
\hline Superior Acetabulum & 11.0 & 12.9 & $<0.001$ & 8.8 & 13.1 & 0.016 \\
\hline $10 \mathrm{~mm}$ Inferior & 19.9 & 8.8 & 0.293 & 18.3 & 21.5 & 0.007 \\
\hline $20 \mathrm{~mm}$ Inferior & 20.9 & 6.2 & 0.311 & 19.6 & 22.3 & 0.001 \\
\hline Most Inferior & 25.1 & 6.2 & $<0.001$ & 23.3 & 26.9 & $<0.001$ \\
\hline
\end{tabular}


technology is limited by cost and prolonged procedure duration $[23,27,30,48]$. Our results indicate that in some patients the use of the superior and inferior acetabular rim to align the acetabular component intra-operatively would lead to positioning it outside all reported 'safe zones'. Using the TAL for alignment however, would be more reliable because it is aligned most closely with the predominant orientation of the acetabulum.

There are a number of advantages associated with using the TAL for alignment of the cup during THA. The cup version is patient specific and independent of the APP, rim angles or specified safe zones $[5,49]$. It is also independent of patient positioning thereby minimizing error in version estimation $[4,8]$.

In this study there was a significant gender difference for acetabular rim and TAL version. Previous studies including those by Lewinnek [32] and Archbold [4] do not describe differences between males and females or patient side in relation to TAL orientation, cup alignment or dislocation rates. However, three of four studies of acetabular morphology have reported between $2.7^{\circ}$ and $5^{\circ}$ greater anteversion of the acetabular rim in females compared to males and no difference between left and right sides which are comparable with our data $[41,50-52]$.

This study is unique in that it, for the first time, provides a noninvasive method for measuring the orientation of the TAL in vivo. However, the study has some limitations. Because the study was retrospective we used scans that had been taken for various reasons and therefore not all accurately imaged the TAL. For this reason not all scans could be included in the study. However, by using a pool of preexisting scans the number of patients measured far exceeds that of any previous study. Lack of numbers in previous studies has been recognized as a limitation in the literature [2]. A second limitation was that the acetabulum was measured at standard heights from superior to inferior rather than individually dividing the acetabulum proportionately for each patient. The height of the femoral head has been reported to have a standard deviation of $13 \mathrm{~mm} \mathrm{[53]} \mathrm{and} \mathrm{this}$ size variation could be extrapolated to the acetabulum. However, this is unlikely to have altered the overall results because the measurements represented the superior and inferior margins as well as the central rim section for all patients. Because we included only hips with normal anatomy these data represent normal hip anatomy. Further investigation of pathological hip anatomy is therefore required but these data provide a useful baseline for future comparison.

This in vivo study has found that the TAL faithfully represents the predominant orientation of the acetabulum and not the relatively retroverted and anteverted superior and inferior margins. Further, these results suggest that utilizing the superior or inferior margins of the acetabulum to orientate the acetabular component in THA could result in an excessively retroverted or anteverted cup, thereby increasing the risk of dislocation and excessive prosthetic wear. These results support the use of the TAL for alignment of the acetabular cup in total hip arthroplasty.

\section{Acknowledgments}

We acknowledge the significant contribution of the following people with thanks and gratitude: Dr J. Scarvell for assistance in the initial planning of the study concept. Dr A. Garg for identification and familiarization of the CT imaging program used in the study. Dr T. Neeman for statistical advice. Dr M. Irani for assistance with assessment of methodological reliability.

\section{References}

1. Archbold HAP, Slomczykowski M, Cairns H, et al. Patient specific cup anteversion in total hip arthroplasty: a computed tomography study investigating the use of the transverse acetabular ligament to control cup placement. Current Orthopaedic Practice 2009;20(1):73.
2. Viste A, Chouteau J, Testa R, et al. Is transverse acetabular ligament an anatomical landmark to reliably orient the cup in primary total hip arthroplasty? Orthop Traumatol Surg Res 2011;97(3):241.

3. Solaiman R, Small T, McNicol D. The use of transverse acetabular ligament (TAL) as an anatomical landmark for acetabular component orientation in primary total hip replacement. J Bone Joint Surg Br 2010;92-B(SUPP I):183.

4. Archbold HA, Mockford B, Molloy D, et al. The transverse acetabular ligament: an aid to orientation of the acetabular component during primary total hip replacement: a preliminary study of 1000 cases investigating postoperative stability. J Bone Joint Surg Br 2006;88(7):883.

5. Murtha PE, Hafez MA, Jaramaz B, et al. Variations in acetabular anatomy with reference to total hip replacement. J Bone Joint Surg Br 2008;90-B(3):308.

6. Mirza SB, Dunlop DG, Panesar SS, et al. Basic science considerations in primary total hip replacement arthroplasty. Open Orthop J 2010;4:169.

7. Kalteis T, Sendtner E, Beverland D, et al. The role of the transverse acetabular ligament for acetabular component orientation in total hip replacement. An analysis of acetabular component position and range of movement using navigation software. J Bone Joint Surg Br 2011;93B(8):1021.

8. Beverland D. The transverse acetabular ligament: optimizing version. Orthopaedics 2010;33(9):631

9. Archbold HAP, Slomczykowski M, Crone M, et al. The relationship of the orientation of the transverse acetabular ligament and acetabular labrum to the suggested safe zones of cup positioning in total hip arthroplasty. Hip Int 2008;18(1):1.

10. Grana WA, Fischer SJ. Total hip replacement. Am Acad Orthop Surg 2011 Available from: orthoinfo.aaos.org.

11. Mihalko WM, Kammerzell S, Saleh KJ. Acetabular orientation with different pelvic registration landmarks. Orthopedics 2009;32(10 Suppl):11 [Research Support Non-U.S. Gov't].

12. Moskal JT. Improving accuracy of acetabular component orientation: avoiding malposition. J Am Acad Orthop Surg 2010;18(5):286.

13. Kennedy JG, Rogers WB, Soffe KE, et al. Effect of acetabular component orientation on recurrent dislocation, pelvic osteolysis, polyethylene wear, and component migration. J Arthroplasty 1998;13(5):530.

14. Patil S, Bergula A, Chen PC, et al. Polyethylene wear and acetabular component orientation. J Bone Joint Surg Am 2003;85-A(Suppl. 4):56 [Case Reports Validation Studies].

15. Brown TD, Callaghan JJ. Impingement in total hip replacement: mechanisms and consequences. Curr Orthop 2008;22(6):376.

16. Nadzadi ME, Pedersen DR, Callaghan JJ, et al. Effects of acetabular component orientation on dislocation propensity for small-head-size total hip arthroplasty. Clin Biomech 2002;17(1):32.

17. Higa M, Tanino H, Abo M, et al. Effect of acetabular component anteversion on dislocation mechanisms in total hip arthroplasty. J Biomech 2011;44(9):1810.

18. Australian Orthopaedic Association National Joint Replacement Registry. Annual report. Adelaide: AOA; 2012 [cited 2013].

19. Austin MS, Rothman RH. Acetabular orientation: anterolateral approach in the supine position. Clin Orthop Relat Res 2008;467(1):112

20. Cogan A, Klouche S, Mamoudy P, et al. Total hip arthroplasty dislocation rate following isolated cup revision using Hueter's direct anterior approach on a fracture table. Orthop Traumatol Surg Res 2011;97:501.

21. D'Lima DD, Chen PC, Colwell Jr CW. Optimizing acetabular component position to minimize impingement and reduce contact stress. J Bone Joint Surg Am 2001;83A(Suppl. 2 Pt 2):87.

22. Derbyshire B. Correction of acetabular cup orientation measurements for $\mathrm{X}$-ray beam offset. Med Eng Phys 2008;30(9):1119 [Evaluation Studies].

23. Echeverri S, Leyvraz PF, Zambelli PY, et al. Reliable acetabular cup orientation with a new gravity-assisted guidance system. J Arthroplasty 2006;21(3):413 [Comparative Study].

24. Epstein NJ, Woolson ST, Giori NJ. Acetabular component positioning using the transverse acetabular ligament: can you find it and does it help? Clin Orthop Relat Res 2010;469(2):412.

25. Hayakawa K, Minoda Y, Aihara M, et al. Acetabular component orientation in intraand postoperative positions in total hip arthroplasty. Arch Orthop Trauma Surg 2009;129:1151.

26. Hohmann E, Bryant A, Tetsworth K. A comparison between imageless navigated and manual freehand technique acetabular cup placement in total hip arthroplasty. J Arthroplasty 2011;26(7):1078.

27. Kanoh T, Hasegawa Y, Masui T, et al. Accurate acetabular component orientation after total hip arthroplasty using an acetabular alignment guide. J Arthroplasty 2010;25(1):81.

28. Ко ВH, Yoon YS. Optimal orientation of implanted components in total hip arthroplasty with polyethylete on metal articulation. Clin Biomech 2008;23:996.

29. Lin F, Lim D, Wixson RL, et al. Validation of a computer navigation system and a CT method for determination of the orientation of implanted acetabular cup in total hip arthroplasty. Clin Biomech 2008;23:1004.

30. Sotereanos NG, Miller MC, Smith B, et al. Using intraoperative pelvic landmarks for acetabular component placement in total hip arthroplasty. J Arthroplasty 2006; 21(6):832.

31. Murray DW. The definition and measurement of acetabular orientation. J Bone Joint Surg Br 1993;75(2):228.

32. Lewinnek GE, Lewis JL, Tarr R, et al. Dislocations after total hip-replacement arthroplasties. J Bone Joint Surg Am 1978;60(2):217 [Research Support, U.S. Gov't, Non-P.H.S.].

33. Wan Z, Malik A, Jaramaz B, et al. Imaging and navigation measurement of acetabular component position in THA. Clin Orthop Relat Res [Review] 2009; 467(1):32. 
34. Biedermann R, Tonin A, Krismer M, et al. Reducing the risk of dislocation after total hip arthroplasty - the effect of orientation of the acetabular component. J Bone Joint Surg Br 2005;87B(6):762.

35. Konrath GA, Hamel AJ, Olson SA, et al. The role of the acetabular labrum and the transverse acetabular ligament in load transmission in the hip. J Bone Joint Surg Am 1998;80(12):1781.

36. Miyoshi H, Mikami H, Oba K, et al. Anteversion of the acetabular component aligned with the transverse acetabular ligament in total hip arthroplasty. J Arthroplasty 2011;00:1.

37. Pooler Archbold HA, Mohammed M, O'Brien S, et al. Limb length restoration during total hip arthroplasty: use of a caliper to control femoral component insertion and accurate acetabular placement relative to the transverse acetabular ligament. Hip Int 2006;16(1):33.

38. Sampatchalit S, Chen L, Haghighi P, et al. Changes in the acetabular fossa of the hip: MR arthrographic findings correlated with anatomic and histologic analysis using cadaveric specimens. Am J Roentgenol 2009;193(2):W127.

39. Ho KWK, Whitwell GS, Young SK. Reducing the rate of early primary hip dislocation by combining a change in surgical technique and an increase in femoral head diameter to $36 \mathrm{~mm}$. Arch Orthop Trauma Surg 2012;132(7):1031.

40. Pearce CJ, Sexton SA, Davies DC, et al. The transverse acetabular ligament may be used to align the acetabular cup in total hip arthroplasty. Hip Int 2008;18(1):7.

41. Vandenbussche E, Saffarini M, Taillieu F, et al. The asymmetric profile of the acetabulum. Clin Orthop Relat Res 2008;466(2):417.

42. Bonneau N, Bouhallier J, Baylac M, et al. Study of the three-dimensional orientation of the labrum: its relations with the osseous acetabular rim. J Anat 2012;220(5): 504 [Research Support, Non-U.S. Gov't].

43. Köhnlein W, Ganz R, Impellizzeri FM, et al. Acetabular morphology: implications for joint-preserving surgery. Clin Orthop Relat Res 2009;467(3):682.
44. Nho J-H, Lee Y-K, Kim HJ, et al. Reliability and validity of measuring version of the acetabular component. J Bone Joint Surg Br 2012;94(1):32.

45. Harris WH. Advances in surgical technique for total hip replacement: without and with osteotomy of the greater trochanter. Clin Orthop Relat Res 1980(146):188.

46. Bosker BH, Verheyen CC, Horstmann WG, et al. Poor accuracy of freehand cup positioning during total hip arthroplasty. Arch Orthop Trauma Surg 2007; 127(5):375.

47. Minoda Y, Ohzono K, Aihara M, et al. Are acetabular component alignment guides for total hip arthroplasty accurate? J Arthroplasty 2010;25(6):986.

48. Lin F, Lim D, Wixson RL, et al. Limitations of imageless computer-assisted navigation for total hip arthroplasty. J Arthroplasty 2011;26(4):596 [Randomized Controlled Trial].

49. Blondel B, Parratte S, Tropiano P, et al. Pelvic tilt measurement before and after total hip arthroplasty. Orthop Traumatol Surg Res 2009;95(8):568 [Comparative Study]

50. Stem ES, O'Connor MI, Kransdorf MJ, et al. Computed tomography analysis of acetabular anteversion and abduction. Skeletal Radiol 2006;35:385.

51. Tohtz SW, Sassy D, Matziolis G, et al. CT evaluation of native acetabular orientation and localization: sex-specific data comparison on 336 hip joints. Technol Health Care 2010;18:129.

52. Atkinson HD, Johal KS, Willis-Owen C, et al. Differences in hip morphology between the sexes in patients undergoing hip resurfacing. J Orthop Surg Res 2010;5(76).

53. Cross MB, Dolan MM, Sidhu GS, et al. The removal of acetabular bone in hip resurfacing and cementless total hip replacement: a comparison using the ratio of the size of the acetabular component to the diameter of the native femoral head. J Bone Joint Surg Br 2012;94(10):1339 [Comparative Study Research Support, N.I.H., Extramural] 